Article

\title{
Effects of Graphene Nanoplatelets and Multiwall Carbon Nanotubes on the Structure and Mechanical Properties of Poly(lactic acid) Composites: A Comparative Study
}

\author{
Todor Batakliev ${ }^{1, *}$, Ivanka Petrova-Doycheva ${ }^{1}$, Verislav Angelov ${ }^{1}$, Vladimir Georgiev ${ }^{2}$, \\ Evgeni Ivanov ${ }^{1,2}{ }^{\oplus}$, Rumiana Kotsilkova ${ }^{1}$, Marcello Casa ${ }^{3}$, Claudia Cirillo ${ }^{4}$, Renata Adami ${ }^{4}{ }^{(}$, \\ Maria Sarno $^{3,4}$ and Paolo Ciambelli ${ }^{3}$ (D) \\ 1 Open Laboratory on Experimental Micro and Nano Mechanics (OLEM), Institute of Mechanics, Bulgarian \\ Academy of Sciences, Acad. G. Bonchev Str. Block 4, 1113 Sofia, Bulgaria; \\ ivanka.petrova01@gmail.com (I.P.-D.); verislav@abv.bg (V.A.); ivanov_evgeni@yahoo.com (E.I.); \\ kotsilkova@yahoo.com (R.K.) \\ 2 Research and Development of Nanomaterials and Nanotechnologies (NanoTech Lab Ltd.), Acad. G. \\ Bonchev Str. Block 4, 1113 Sofia, Bulgaria; vladofe@gmail.com \\ 3 Narrando Srl, Via Giovanni Paolo II, 132, 84084 Fisciano, Italy; mcasa@unisa.it (M.C.); \\ msarno@unisa.it (M.S.); pciambelli@unisa.it (P.C.) \\ 4 Department of Industrial Engineering and Centre NANO_MATES, University of Salerno, Via Giovanni \\ Paolo II, 132, 84084 Fisciano, Italy; clcirillo@unisa.it (C.C.); radami@unisa.it (R.A.) \\ * Correspondence: todorbat@gmail.com; Tel.: +359-2-9792594
}

Received: 15 December 2018; Accepted: 28 January 2019; Published: 30 January 2019

\begin{abstract}
Poly(lactic acid)/graphene and poly(lactic acid)/carbon nanotube nanocomposites were prepared by an easy and low-cost method of melt blending of preliminary grinded poly(lactic acid) (PLA) with nanosized carbon fillers used as powder. Morphological, structural and mechanical properties were investigated to reveal the influence of carbon nanofiller on the PLA-based composite. The dependence of tensile strength on nanocomposite loading was defined by a series of experiments over extruded filaments using a universal mechanical testing instrument. The applying the XRD technique disclosed that compounds crystallinity significantly changed upon addition of multi walled carbon nanotubes. We demonstrated that Raman spectroscopy can be used as a quick and unambiguous method to determine the homogeneity of the nanocomposites in terms of carbon filler dispersion in a polymer matrix.
\end{abstract}

Keywords: nanocomposites; carbon nanofillers; poly(lactic) acid (PLA); tensile strength; structure properties

\section{Introduction}

Last decade, many scientific efforts have been made for the synthesis of multifunctional polymer nanocomposites that take advantage of the unique mechanical and structural properties of new graphitic forms as graphene (GNPs) and multiwall carbon nanotubes (MWCNTs) [1-5]. There are a lot of studies on carbon composites based on a wide range of polymers, reported in the literature as polycarbonate [6], nylon [7], poly(methyl methacrylate) [8], epoxy resin [9], poly(vinyl alcohol) [10], polystyrene [11], polycaprolactone [12], poly(propylene) [13], and poly(lactic acid) [14,15]. One of the main parameters that influences the composite properties is the distribution/dispersion of the carbon nanofillers in conjunction with their weight percentage loading in the polymer matrix $[16,17]$. X-ray diffractometry (XRD), as a safe method of nanocomposite characterization, has been used to reveal 
information on the existence of GNPs in the form of individual graphene sheets in epoxidized palm oil blends [18], to disclose the effect of sonication time on the dispersion ability of graphene in the PLA matrix [19], to confirm intactness and reliable distribution of reduced graphene oxide (rGO) as graphene sheet layers into a polymer composite [20], and to study the influence of carbon nanofiller on the semi-crystalline structure of PLA and PBAT [21]. Abdal-Hay et al. [22] reported that PLA and nanocomposites containing different CNT concentrations exhibited nearly the same diffraction peaks at slightly different locations.

Raman spectroscopy provides molecular morphology analysis, giving information on the composite material structure by evaluation of relevant vibrational features and could be used to characterize the degree of graphene or nanotube dispersion. Bounos et al. [23] investigated MWCNT loading, excitation laser power and temperature as parameters affecting the frequency of the Raman bands and their intensity. They reported that in the specific case of isotactic polypropylene (iPP), any interaction of the carbon nanotubes with the polymeric host has minimal effect on the frequency of the MWCNT's G band $\left(\sim 1584 \mathrm{~cm}^{-1}\right)$; the same holds for the influence of residual stresses acting on the MWCNTs. The parameter that primarily altered the CNT's Raman bands frequency was temperature, determined by the excitation laser intensity, the MWCNTs concentration and the thermal properties of the polymer matrix. This was demonstrated by confocal micro-Raman spectra collected from agglomerates and from micro-Raman spectra of samples containing either poorly or well dispersed MWCNTs.

Raman confocal spectroscopy has been used for characterization of MWCNTs embedded in PLA fibers in the absence of a chemical interaction between them [24]. By means of confocal images, agglomerates of carbon nanotubes have been noticed, even after solution ultrasound sonication. The Raman spectrum of MWCNTs, as expected, showed the graphitic D, G and $\mathrm{G}^{\prime}$ bands at 1362, 1590 and $2683 \mathrm{~cm}^{-1}$, respectively.

The structure and properties of MWCNT-grafted silica nanohybrids were established by means of diverse physical methods, including Raman spectroscopy [25]. In this study, Raman spectroscopy was used to detect amorphous and crystalline phases in MWCNT samples with various degrees of graphitization. The characteristic peaks of the MWCNTs at $1326 \mathrm{~cm}^{-1}$ (D-band) and $1580 \mathrm{~cm}^{-1}$ (G-band) were attributed to amorphous carbon and well-graphitized MWCNTs, respectively. Notably, the broad peak registered at $1326 \mathrm{~cm}^{-1}$ was related to the presence of a defective graphitic layer or carbon particles.

In a recent article [26], the influence of filler size on the properties of poly(lactic acid) (PLA)/graphene nanoplatelets (GNP) nanocomposites were investigated. Morphological, thermal, mechanical, and electrical properties were studied to reveal the influence of particle size. Electron microscopy and X-ray diffraction showed well dispersed small GNP (GNP-S) particles up to $10 \mathrm{wt} \%$ loading, while large GNP (GNP-L) particles started to agglomerate at loadings $\geq 7 \mathrm{wt} \%$. Notably, composites with GNP-L demonstrated a much stronger peak than those with GNP-S at the same loading, indicating that large GNP-L fillers induce higher polymer crystallinity than small GNP-S in the composites. The XRD results also demonstrated that there is no significant change in PLA crystallinity with the incorporation of both GNP types, regardless of their size.

X-ray powder diffraction analyses were carried out over polylactide (PLA)/graphene nanocomposites, prepared by a facile and low-cost method of solution blending of PLA with liquid-phase exfoliated graphene using chloroform as a mutual solvent [27]. The dispersion of graphene in a PLA matrix has been examined by physical methods as SEM, XRD and TEM. The authors reported that the XRD pattern of PLA-based nanocomposites loaded with $0.1 \mathrm{wt} \%$ graphene sheets (GSs) was almost the same as that of pure PLA, in which two characteristic diffraction peaks are shown at 16.3 and $18.7^{\circ}$, corresponding to (200)/(110) and (203) planes of crystalline PLA, respectively. The diffraction peak at $26^{\circ}$ corresponding to graphite layer structure (002) was not observed in GSs due to the exfoliation. The scattering intensity profile did not reveal the presence of the diffraction 
peak of graphite, suggesting that the GSs do not aggregate in a PLA matrix. As suggested by some authors, this result indicates that the dispersion of GSs in a PLA matrix is close to single-sheet level.

In another paper [28], D. Singh et al. made research over the diameter dependence of interwall separation and strain in multiwalled carbon nanotubes probed by X-ray diffraction and Raman scattering studies. The authors did a systematic study on the diameter dependent spectral features in X-ray diffraction (XRD) and Raman scattering studies of multiwalled carbon nanotubes (MWCNTs) of various diameters in the range 5-100 nm. Analysis of the XRD patterns showed an exponential decrease in $\mathrm{d}_{002}$ interlayer spacing with increasing tube diameter, in close agreement with the HRTEM results. Analysis of Raman and XRD data disclosed that the lowest diameter $(7 \mathrm{~nm})$ MWCNTs have features similar to those of the single walled nanotubes, while the spectral features are distinctly different for higher diameter MWCNTs.

Relationships between structure and properties of nanocomposite materials can be made through a combination of structural investigations (such as Raman spectroscopy and X-ray diffraction) and mechanical tests in order to have better understanding of these nanocomposites. The effects of increasing filler content on the macro-mechanical properties of polymer nanocomposites can be investigated through tensile, flexural or impact tests. Some previous results for mechanical properties of PLA reinforced with carbon nanostructures as graphene [29,30], carbon nanotubes [31] and both nanofillers [32] have been reported in the literature. The incorporation of carbon fillers in a polymer matrix is expected to improve the mechanical properties, especially when carbon nanotubes are used as a reinforcing material [33].

The aim of the present study was to estimate the influence of two different carbon nanofillers and the relevant loading amount on the structure and homogeneity of PLA-based nanocomposites. Another challenge was to elucidate the dispersion degree of both carbon nanofillers at all composites loadings, as well as to study the effect of GNP and MWCNTs on the crystal structure of PLA (at high filler contents). The novelty in this study is related to an important detail in the preparation method consisting of preliminary grinding of PLA and then using PLA as a powder during melt mixing of the polymer with the carbon nanofiller.

\section{Materials and Methods}

\subsection{Materials}

Ingeo ${ }^{\mathrm{TM}}$ Biopolymer PLA-3D850 (Nature Works) with MFR 7-9 g/10 $\min \left(210^{\circ} \mathrm{C}, 2.16 \mathrm{~kg}\right)$ and $\mathrm{M}_{\mathrm{w}} \sim 60000 \mathrm{~g} / \mathrm{mol}$ was purchased from Nature Works, Minnetonka, MN, USA.

MWCNT (NC7000, from Nanocyl, Sambreville, Belgium): Diameter (OD) $9.5 \mathrm{~nm}$; Length $1.5 \mu \mathrm{m}$, Purity $90 \%$; Specific surface area SSA $=250-300 \mathrm{~m}^{2} / \mathrm{g}$; Volume resistivity $10^{-4} \Omega \cdot \mathrm{cm}$ and TNGNP (Graphene Nanoplatelets, TimesNano, Chengdu, China) - average thickness $<4-20 \mathrm{~nm}$ and diameter of $\sim 5-10 \mu \mathrm{m}$; Purity $99.5 \%$; Volume Resistivity $4 \times 10^{-4} \Omega \cdot \mathrm{cm}$ were supplied from TimesNano, Chengdu, China.

\subsection{Preparation of Nanocomposites}

The compounds were made by means of the melt extrusion technique. The PLA pellets were grinded and then used as powder. Mono-filler nanocomposites were synthesized that way, containing graphene or carbon nanotubes and having filler content from 0 to $9 \mathrm{wt} \%$. All produced and tested compounds are listed in Table 1. 
Table 1. List of PLA-based nanocomposites.

\begin{tabular}{ccccc}
\hline No. & Sample Index & PLA Content $\mathbf{( w t} \%)$ & MWCNT Content $\mathbf{( w t} \%)$ & GNP Content $(\mathbf{w t} \mathbf{\%})$ \\
\hline 1 & 1.5GNP/PLA & 98.5 & - & 1.5 \\
2 & 3GNP/PLA & 97 & - & 3 \\
3 & 6GNP/PLA & 94 & - & 6 \\
4 & 9GNP/PLA & 91 & 1.5 & 9 \\
5 & 1.5MWCNT/PLA & 98.5 & 3 & - \\
6 & 3MWCNT/PLA & 97 & 6 & - \\
7 & 6MWCNT/PLA & 94 & 9 & - \\
8 & 9MWCNT/PLA & 91 & - & - \\
9 & PLA & 100 & & - \\
\hline
\end{tabular}

\subsection{Preparation of Test Samples}

Circular cross-section samples with a diameter of about $1.75 \mathrm{~mm}$ and length of $5 \mathrm{~cm}$ were cut from extruded filaments and then applied for tensile tests. The samples needed for Raman and XRD analysis were hot pressed with a thickness of $\sim 1 \mathrm{~mm}$ and diameter of $20 \mathrm{~mm}$.

\subsection{Experimental Methods}

Two types of monofilled nanocomposites (MWCNT/PLA and GNP/PLA) were used for a series of tensile tests in order to evaluate the material's mechanical characteristics. The experiments were carried out on UMT-2 Universal Tester modular system (Bruker, Billerica, MA, USA) developed by Bruker. Tensile tests were performed by using a 1-100 kg (1000 N) force sensor. The set tensile speed was $1 \mathrm{~mm} / \mathrm{min}$ at room temperature. The standard error was determined by testing 7 samples of each composition. During the experiment, the working section of the sample under tension was exactly $1 \mathrm{~cm}$.

The $\mathrm{KBr}$ technique was applied for determining the FT-IR spectra of the samples, in the scanning range from 4000 to $400 \mathrm{~cm}^{-1}$, by using a Vertex 70 instrument (Bruker Corporation).

Single spectra were taken on an inVia confocal Raman microscope spectrometer Renishaw, using a 50x excitation green argon ion laser with $1800 \mathrm{~L} / \mathrm{mm}$ grating. The power radiation was $12.5 \mathrm{~mW}$ at $514 \mathrm{~nm}$ wavelength edge laser physics and 10 seconds integration time. A laser beam with a diameter of approximately $2.5 \mu \mathrm{m}$ was focused onto the surface of each nanocomposite sample.

X-ray powder and nanocomposite diffraction (XRD) analyses were carried out on a Bruker D8 Advance diffractometer (Billerica, MA, USA ) at $40 \mathrm{kV}$ and $40 \mathrm{~mA}$ with $\mathrm{Cu} \mathrm{K} \alpha$ radiation $(\lambda=0.15418 \mathrm{~nm})$, and the diffraction data were recorded for $2 \theta$ angles between $0^{\circ}$ and $50^{\circ}$ applying a scanning rate of $4^{\circ} \mathrm{min}^{-1}$.

The morphology of the nanocomposites was observed by a field emission scanning electron microscope (FESEM, mod. LEO 1525, Carl Zeiss SMT AG, Oberkochen, Germany). Hot pressed samples were immersed in liquid nitrogen, then cut to get the cross-section and finally coated with gold (layer thickness $250 \AA$ Å) using a sputter coater (mod. B7341, Agar Scientific, Stansted, UK).

\section{Results and Discussion}

\subsection{Infrared Spectroscopy Analysis}

In the IR-spectrum of GNP, bands corresponding to stretching vibrations of $\mathrm{CH}$ group at $2853 \mathrm{~cm}^{-1}$ and $2920 \mathrm{~cm}^{-1}$ could be observed (see Figure 1). The bands at $3444 \mathrm{~cm}^{-1}$, at $1649 \mathrm{~cm}^{-1}$ and $1109 \mathrm{~cm}^{-1}$ are due to stretching vibrations of the $-\mathrm{OH}, \mathrm{C}=\mathrm{O}$ and $\mathrm{C}-\mathrm{O}$ adsorption groups. Overall, these bands, which are typical of non-functionalized materials [34], indicate that GNPs contain defects. 


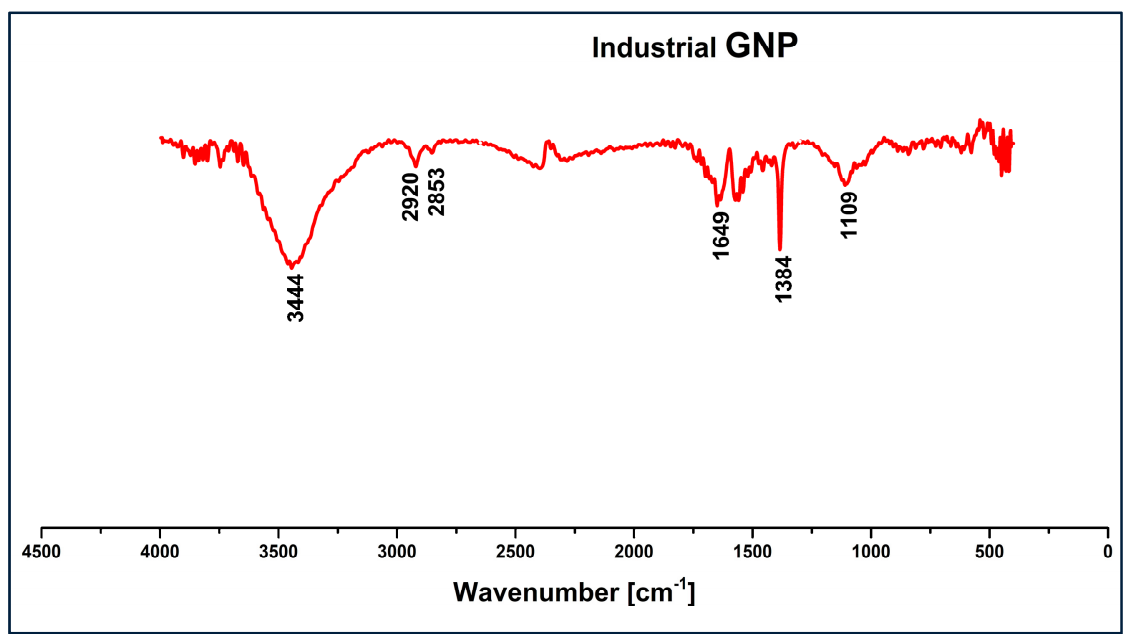

Figure 1. IR spectrum of GNPs.

The IR spectrum of carbon nanotubes (Figure 2), showed intense bands corresponding to stretching vibrations of $-\mathrm{OH}, \mathrm{C}=\mathrm{O}$ and $\mathrm{C}-\mathrm{O}$, together with new bands corresponding to carboxyl groups $(-\mathrm{COOH}): v(\mathrm{C}=\mathrm{O})$ at $1741 \mathrm{~cm}^{-1}$ and $\mathrm{C}=\mathrm{O}$ bond at $1028 \mathrm{~cm}^{-1}$, indicating a MWCNTs surface functionalization. These typical bands, with slight variations in wavelength, can be found for carbon nanotube oxidized in different ways [35].

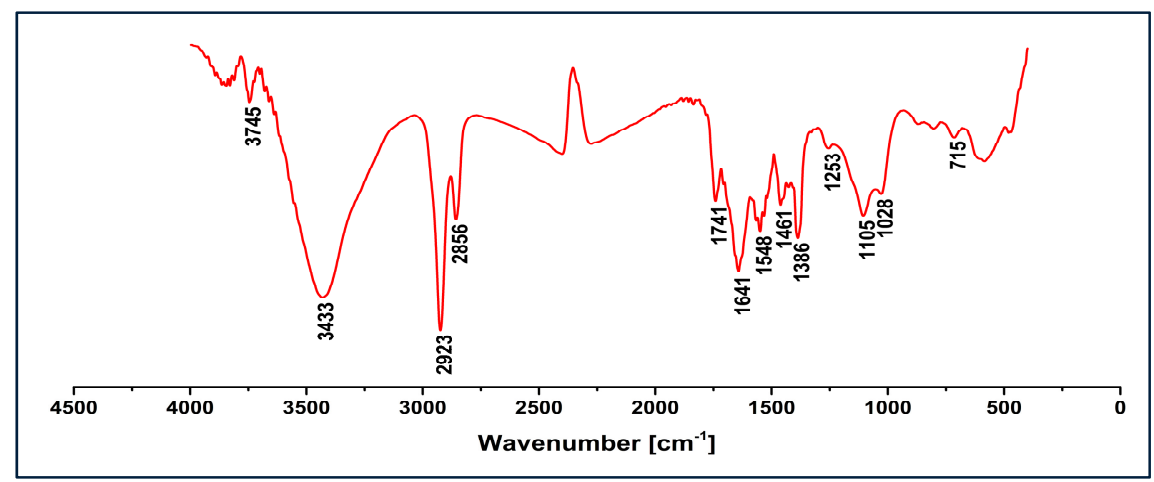

Figure 2. IR spectrum of multi walled carbon nanotubes.

\subsection{Raman Analysis}

Raman spectroscopy has become a standard characterization tool for carbon nanostructures [36-39]. Tensile, compressive and shear stress applied to carbon nanotubes induce strain, leading to changes in the $\mathrm{C}-\mathrm{C}$ bond vibrations, which strongly affect the Raman spectrum [40]. Stress induced changes in peak positions and intensities have been observed for individual carbon nanotubes [41], SWCNT bundles [42] and nanotube-polymer composites [43]. Normalized Raman spectra of the nanocomposites with increasing MWCNTs and GNPs concentration including pristine nanofiller as a reference are depicted in Figures 3 and 4. In all single spectra, the main Raman bands-G, D and 2D, or also denoted as $G^{\prime}$, band have been registered. The $1582 \mathrm{~cm}^{-1}$ band of graphene is known as the $G$ band or tangential band and originates from in-plane vibration of $\mathrm{sp}^{2}$ carbon atoms. The band at about $2700 \mathrm{~cm}^{-1}$, which is recognized as the $\mathrm{G}^{\prime}$ or $2 \mathrm{D}$ band, is much more intense than the $\mathrm{G}$ band in graphene compared to graphite or to multilayer graphene. This band is a second-order overtone mode and does not represent a disorder-induced mode. The 2D band has frequently been used to study MWCNT-polymer interfacial stress transfer. The 2D peak is an overtone of the D band, resulting from a two-phonon double-resonant Raman process [44]. The D band at around $1350 \mathrm{~cm}^{-1}$ is often referred as disorder band or defect band and its intensity relative to the $G$ 
band intensity is often used as a measure of carbon nanotubes quality. All Raman results concerning monofiller PLA-based nanocomposites are summarized in Figures 3 and 4, and Table 2.

The presence of MWCNTs in the composites is supported by the characteristic D, G, and 2D modes of MWCNTs (Figure 3). D, G, and 2D modes of the MWCNT/PLA composites exhibit positional upshift, more pronounced in the 2D band, as compared to the pure MWCNTs itself. Shifts to higher-frequencies, especially for the G band, have been reported in MWCNTs composites [45]. This blue shift has been attributed to a disentanglement and dispersion of the CNT bundles in the polymer matrix, decreasing nanotube-nanotube interactions. The application of a deformation to CNTs results in a change in the $\mathrm{C}-\mathrm{C}$ bond vibrations, leading to a change in the vibrational frequencies of the normal modes and thus to Raman band shifts. Strain-induced frequency changes have been already reported for MWCNTs composites [43]. In terms of the relative Raman intensity, evaluated against the G mode intensity, and the full width at half maximum intensity (FWHM), we can observe different distinct behaviors: the D intensity decreased substantially upon rising carbon nanotube content in the composite, whereas the 2D mode exhibits a cutback of the relative intensity as well as a significant reduction of FWHM. These changes can be due to the interaction between PLA and carbon nanotubes. It is worth noticing, that the resonances of pure PLA, due to $\mathrm{C}-\mathrm{CH}_{3}$ stretching at about $1042 \mathrm{~cm}^{-1}$ and $-\mathrm{CH}_{3}$ rocking mode at about $1127.4 \mathrm{~cm}^{-1}$, were red-shifted by $2.1,1.3$, and $1.8 \mathrm{~cm}^{-1}$ in the Raman spectrum of $3 \mathrm{wt} \%$ MWCNT/PLA composite regarding the spectrum of $1.5 \mathrm{wt} \%$ MWCNT/PLA composite, indicating that the interaction of MWCNTs with the polymer occurs through C-CH3 groups [46,47], see Figure 3b.

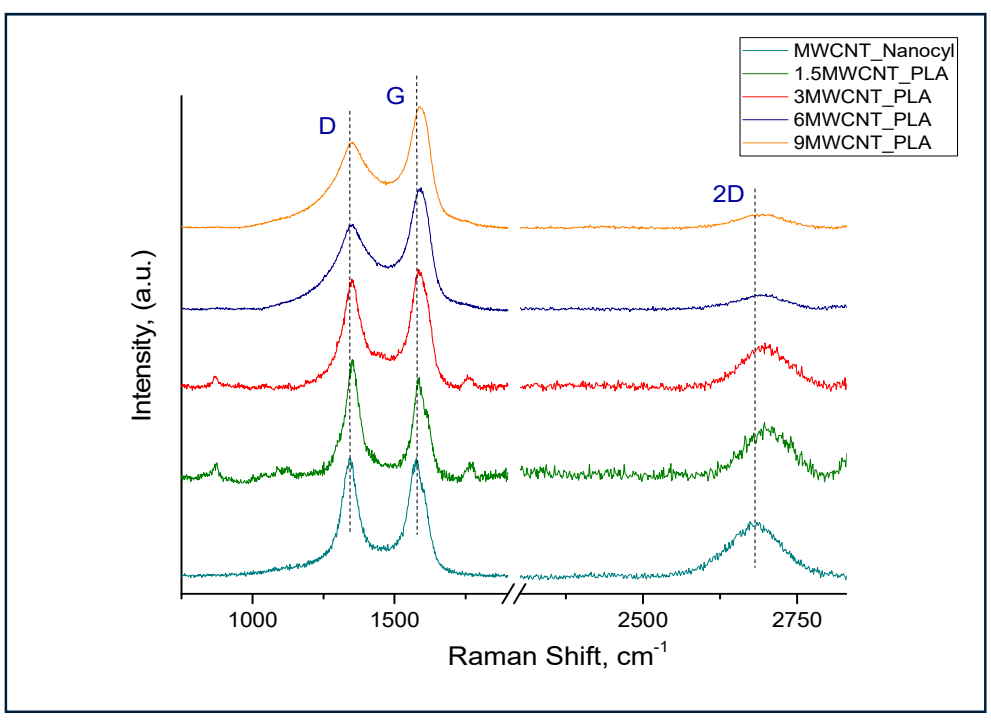

(a)

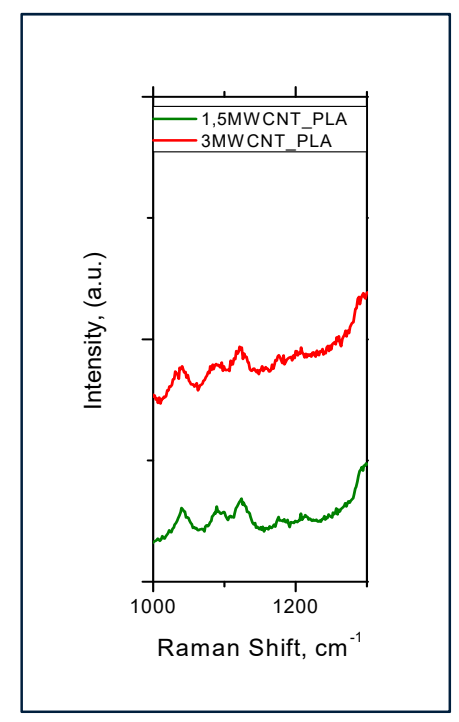

(b)

Figure 3. Normalized Raman spectra of nanocomposites with rising MWCNTs concentration and pristine nanotubes as a reference (a), enlargement between 1000 and $1500 \mathrm{~cm}^{-1}$ (b).

As already mentioned, the 2D band of the nanocomposites in Figure 3 is barely shifted to higher Raman frequencies, compared with the 2D band of pure carbon nanotubes. A possible reason for this could be as well the relatively low filler concentration in the polymer matrix compared to the neat MWCNTs [23]. When the carbon nanotubes are multi walled, their diameter becomes larger, so the lattice strain is reduced, leading to a decline in the number of $\mathrm{sp}^{3}$ hybridized carbon, which means the tubular structure is not so stable [28]. The weak blueshift of the $\mathrm{G}$ band at $6 \mathrm{wt} \%$ and $9 \mathrm{wt} \% \mathrm{MWCNT}$ loadings could be understood in terms of the strain effect caused by the interaction between carbon nanotubes and the PLA matrix. 


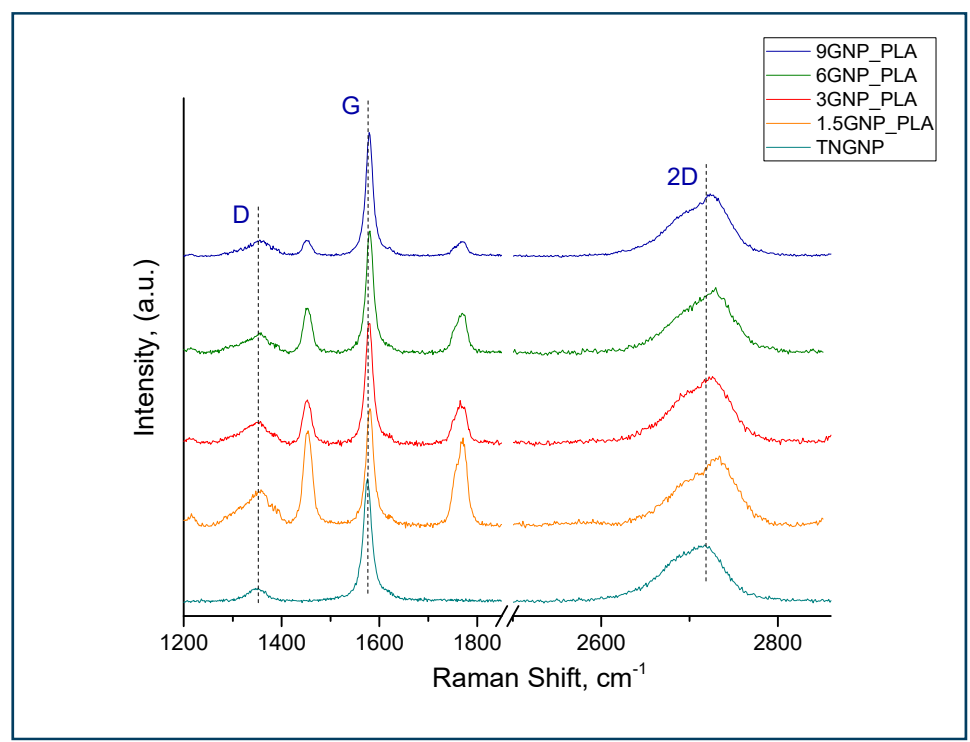

Figure 4. Normalized Raman spectra of nanocomposites with growing GNPs concentration and pristine graphene as reference.

As the number of graphitic layers increases, the interaction between these layers becomes significant, reflecting in the appearance of a shoulder over the 2D band in the Raman spectra of GNP/PLA nanocomposites (Figure 4). This shoulder shifts the position of the 2D band to the higher frequencies of the spectrum. Concerning graphene samples, the small differences in the $\mathrm{G}$ band position up to $3 \mathrm{~cm}^{-1}\left(1575-1578 \mathrm{~cm}^{-1}\right)$ are suggested to be within the range of fluctuations caused by unintentional electron or hole doping effects [48]. It was found that the influence of the PLA structure on the Raman spectra of the nanocomposites decreases with rising carbon filler loading.

The $\mathrm{I}_{2 \mathrm{D}} / \mathrm{I}_{\mathrm{G}}$ ratio shows the graphene quality. Regarding high quality defect-free graphene, this ratio will be equal to 2 (single or few layers graphene). The defined $\mathrm{I}_{2 \mathrm{D}} / \mathrm{I}_{\mathrm{G}}$ ratios of TNGNP and GNP/PLA nanocomposites are rather a hint for the presence of multilayer graphene in the composite structure (Table 2). Mapping Raman analysis was carried out on each sample, acquiring spectra at least on three surface sample positions, in order to have a better picture of nanocomposite homogeneity.

Table 2. Raman intensities ratios of monofiller nanocomposites.

\begin{tabular}{ccc}
\hline Sample & $\mathbf{I}_{\mathbf{D}} / \mathbf{I}_{\mathbf{G}}$ & $\mathbf{I}_{\mathbf{2}} / \mathbf{I}_{\mathbf{G}}$ \\
\hline TNGNP & $0.10 \pm 0.01$ & $0.45 \pm 0.01$ \\
MWCNT_Nanocyl & $1.00 \pm 0.01$ & $0.55 \pm 0.02$ \\
1.5MWCNT/PLA & $1.14 \pm 0.03$ & $0.50 \pm 0.01$ \\
3MWCNT/PLA & $0.85 \pm 0.03$ & $0.33 \pm 0.02$ \\
6MWCNT/PLA & $0.71 \pm 0.002$ & $0.14 \pm 0.01$ \\
9MWCNT/PLA & $0.72 \pm 0.005$ & $0.12 \pm 0.01$ \\
1.5GNP/PLA & $0.30 \pm 0.06$ & $0.63 \pm 0.03$ \\
3GNP/PLA & $0.18 \pm 0.04$ & $0.50 \pm 0.04$ \\
6GNP/PLA & $0.15 \pm 0.002$ & $0.49 \pm 0.03$ \\
9GNP/PLA & $0.11 \pm 0.02$ & $0.48 \pm 0.04$ \\
\hline
\end{tabular}

Peaks ratio calculations disclosed that even the pristine GNP and MWCNT are not fully homogeneous. However, a high level of homogeneity occurred in the nanocomposites. That was confirmed by the low standard deviations in the $\mathrm{I}_{\mathrm{D}} / \mathrm{I}_{\mathrm{G}}$ and $\mathrm{I}_{2 \mathrm{D}} / \mathrm{I}_{\mathrm{G}}$ ratios for each sample, showing a high level of homogeneity in the nanocomposites structure (see Table 2). The fewer lattice defects led to a lower $\mathrm{I}_{\mathrm{D}} / \mathrm{I}_{\mathrm{G}}$ value. An indication of the low amount of structural defects in MWCNT/PLA nanocomposites is the narrow $\mathrm{I}_{\mathrm{D}} / \mathrm{I}_{\mathrm{G}}$ ratio, mostly concerning the higher MWCNTs loadings that could 
signify good dispersion of carbon nanotubes in the polymer matrix. The peak intensity ratios $\mathrm{I}_{\mathrm{D}} / \mathrm{I}_{\mathrm{G}}$ of graphene nanocomposites are slightly higher than that of TNGNP, suggesting the formation of more basal plane and edge defects in the carbon filler present in GNP/PLA that could enhance the interface interactions in the composite. Nevertheless the low $\mathrm{I}_{\mathrm{D}} / \mathrm{I}_{\mathrm{G}}$ values of GNP/PLA nanocomposites, really close to the $\mathrm{I}_{\mathrm{D}} / \mathrm{I}_{\mathrm{G}}$ ratio of pure graphene nanoplatelets, can be an indication that the structure of GNP has been well preserved during melt extrusion processing. The standard deviations for all $\mathrm{I}_{\mathrm{D}} / \mathrm{I}_{\mathrm{G}}$ and $\mathrm{I}_{2 \mathrm{D}} / \mathrm{I}_{\mathrm{G}}$ ratios have been taken into consideration when presenting the data in Table 2.

\subsection{XRD Analysis}

Pristine graphene exhibits a basal reflection (002) sharp peak at $2 \theta=27.0^{\circ}$ corresponding to a d spacing of $3.370 \AA$ in graphite layer structure (Figure 5). The graphene showed a more intensive peak than the carbon nanotubes pattern at $2 \theta=26.26^{\circ}$, indicating a more crystalline structure for GNP. Considering the spectral profile of MWCNT, the weak broad XRD peak at $2 \theta=43.54^{\circ}$ is assigned to graphitic (100) crystalline lattice.

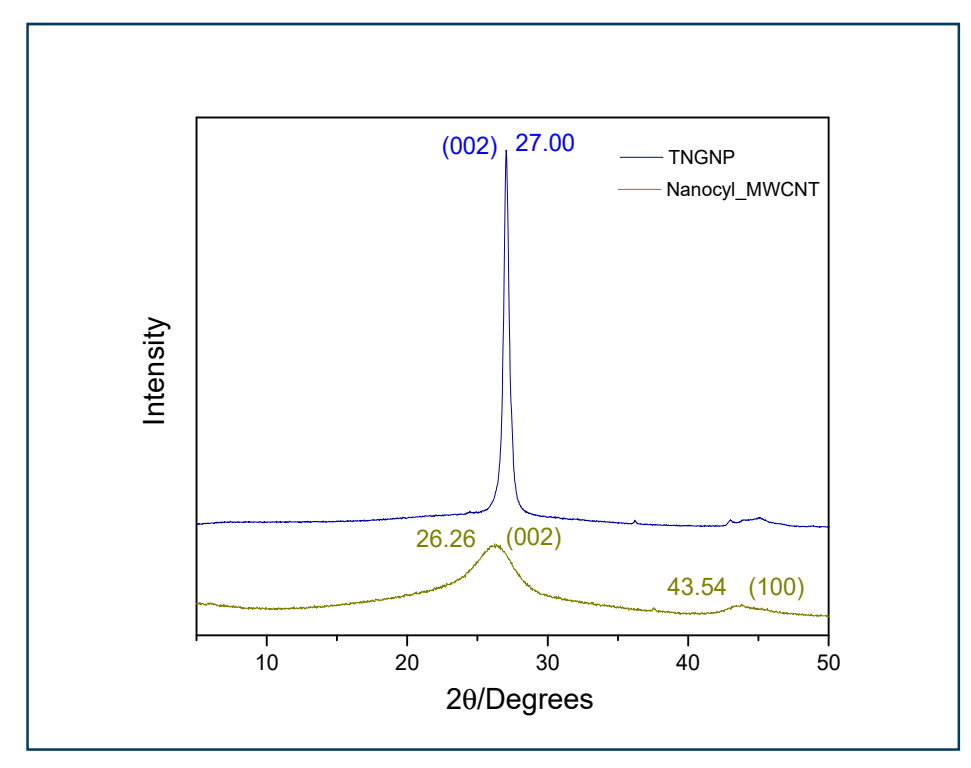

Figure 5. XRD patterns of pure graphene and carbon nanotubes.

A broad amorphous peak was observed as result of neat PLA XRD analysis at around $20.0^{\circ}$ combined with a weak sharp peak appearing at $17.2^{\circ}$ (Figure 6). This is an indication of scattering in the polymer matrix and confirms that the neat PLA has a partially pseudo orthorhombic $\alpha$ crystalline structure with a left handed $10 / 3$ helices chain conformation but predominantly it is a biodegradable polymer possessing an amorphous microstructure. The analysis of the patterns in Figure 6 is evidence that the intensity of the GNPs (002) peak increases with increasing GNPs loading in PLA, as expected. Regarding the XRD analysis of the $9 \mathrm{wt} \%$ GNP/PLA composite, a distinct diffraction is observed at $27.2^{\circ}$, relating to an interlayer spacing of $0.33 \mathrm{~nm}$, based on the Bragg's law, which is associated with the graphitic (002) plane. On the other hand, the position change indicates that the spacing between graphene nanoplatelets in the composites shortened (from an interlayer spacing of $0.34 \mathrm{~nm}$ of $6 \mathrm{wt} \%$ GNP/PLA to $0.33 \mathrm{~nm}$ for $9 \mathrm{wt} \%$ GNP/PLA based on Bragg's law). The addition of GNPs affects the semi-crystalline structure of the polymer: the crystalline PLA peak at $2 \theta \sim 17.2^{\circ}$ in PLA/GNP nanocomposites is absent. 


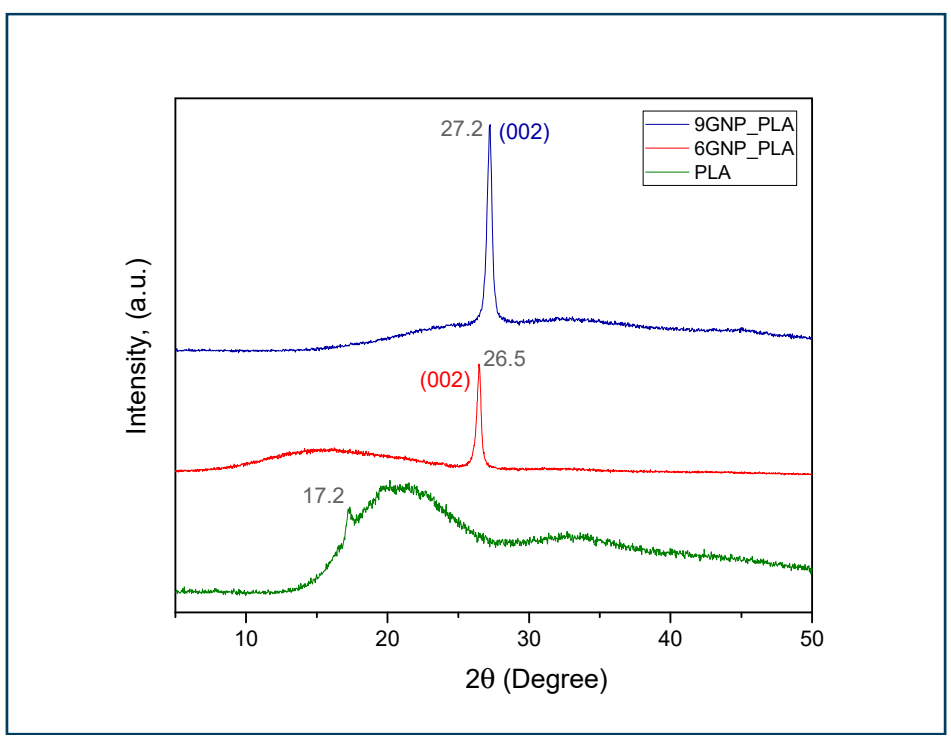

Figure 6. X-ray diffraction of nanocomposites with rising graphene concentration and neat PLA as a reference.

The high intensity recorded at $9 \mathrm{wt} \%$ GNP loading could be attributed to a relatively intense number of graphene layers organized in stacks. The X-ray diffraction of $6 \mathrm{wt} \% \mathrm{GNP} / \mathrm{PLA}$ nanocomposites revealed a less intensive graphite (002) pattern and weak feature of the broad PLA peak. The disappearance of PLA crystallinity with growing graphene content can be explained as a result of interfacial effects influencing the PLA semi-crystalline structural order. The XRD technique could provide information about the stacking thickness of the GNP crystallites. The average pristine nanoplatelet thickness as well as the size of the incorporated graphene was calculated by using the Scherrer equation. It was found that pure GNP has a thickness of about $\sim 80 \mathrm{~nm}$. This dimension remains roughly the same in the composite having $9 \mathrm{wt} \% \mathrm{GNP}(\sim 82 \mathrm{~nm})$.

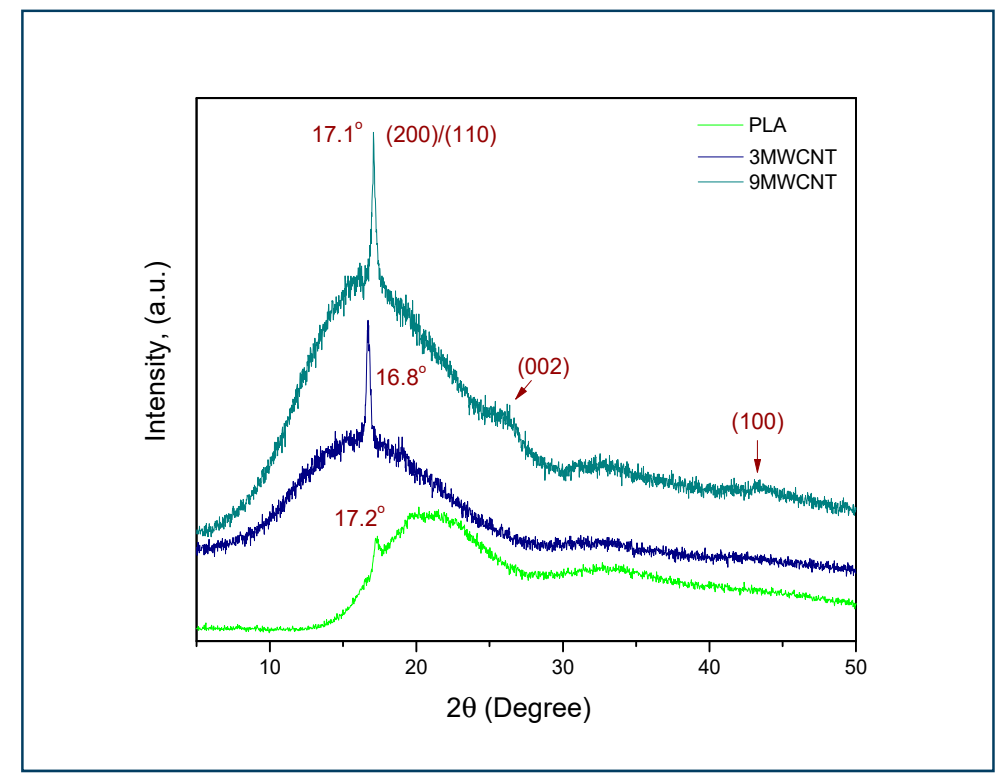

Figure 7. X-ray diffraction of nanocomposites with rising carbon nanotubes concentration and neat PLA as a reference.

The influence of the carbon nanotubes loading on the polymer crystallinity is prominent in Figure 7. The improvement of the sharp PLA peak at about $17.0^{\circ}$ is more significant for the compound 
loaded with $9 \mathrm{wt} \%$ MWCNT and less intense for the composite possessing $3 \mathrm{wt} \%$ MWCNT. Both composite diffraction patterns are an indication of more crystalline structure compared to the neat PLA. Graphitic (002) and (100) patterns are visible mostly for the $9 \mathrm{wt} \%$ MWCNT/PLA composite, which could be a sign of good carbon nanotube dispersion in the polymer matrix. This behavior, which shows a different trend compared to that of GNP, can be attributed to the dimensionality of the nanoparticles and probably also to the different degree of functionalization of the nanocarbons, where carboxyl groups can act as crystallinity centers in the polymer matrix. Indeed, nanofillers are reported to act in nucleating in nanocomposites [49], with crystalline layers covering the filler [50]. On the other hand, functional groups can improve crystallization [51], indeed only one nucleating site is needed, for the polymer, to start crystallization. Moreover, polymer chains crystalline formation continues more easily on different nanoparticle dimensionalities, which can influence the crystallization behavior of the polymer, (i.e. the polymer chains align along the nanofiller surface) [52].

\subsection{Tensile Test Analysis}

There are three possible types of interactions for composites that have nanofiller in their structure (polymer-nanofiller, nanofiller-nanofiller, and interface-polymer interactions), but the mechanism and the magnitude of the load transfer between polymer matrices and the nanofiller are still unclear concerning mechanical properties.

Considering the influence of carbon nanofillers on the macromechanical properties of nanocomposites, the main and most important tensile mechanical characteristics; ultimate (tensile) strength, elongation at ultimate strength and Young's modulus, have been compared. The dependence of ultimate strength as a function of filler content in MWCNT/PLA and GNP/PLA nanocomposites is shown in Figure 8a.

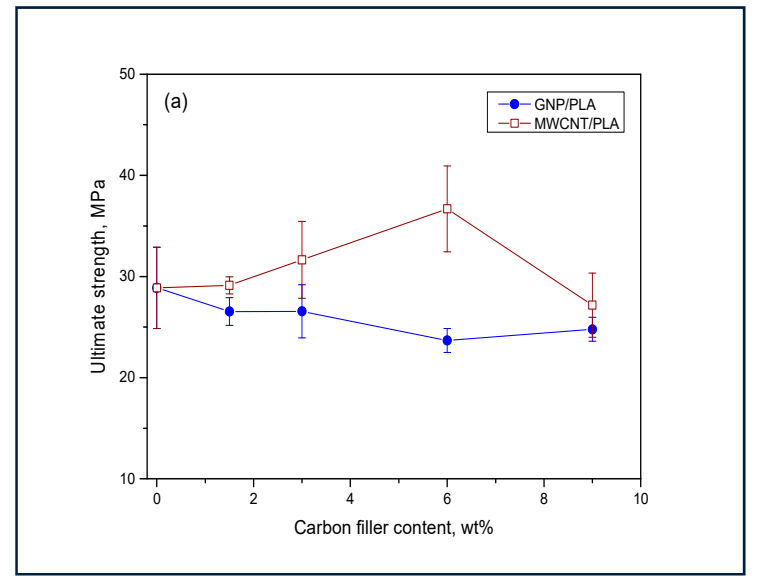

(a)

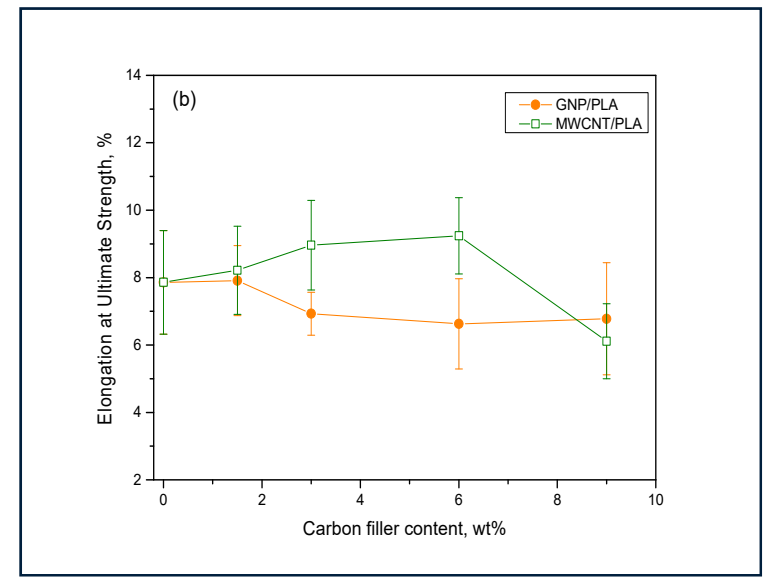

(b)

Figure 8. Tensile strength (a) and elongation at ultimate strength (b) vs. carbon filler content for MWCNT/PLA and GNP/PLA nanocomposites.

The nanocomposites possessing GNP in the PLA matrix exhibit a trend of a slight decrease in ultimate strength as well as in elongation at a break when increasing the content filler. A possible reason for this could be a poor dispersion of graphene in the polymer volume and/or changes in polymer crystallinity due to the nanoparticles addition. The character of the curve describing nanocomposites with MWCNT/PLA is quite different. The incorporation of MWCNT significantly raises the tensile strength and elongation at ultimate strength parameters up to $6 \mathrm{wt} \%$ carbon filler content, see Figure 8 . Above a $20 \%$ increase in the tensile strength of the MWCNT/PLA composite is observed at $6 \mathrm{wt} \%$ carbon nanotubes content compared to the neat PLA. The rising of carbon nanotubes loading from $1.5 \mathrm{wt} \%$ to $6 \mathrm{wt} \%$ enhances the elongation at ultimate strength, as can be seen in Figure $8 \mathrm{~b}$. This is due to the interfacial polymer-filler interaction related to the distinct hybrid structure between MWCNT 
and polymer chains. The lower values of ultimate strength and elongation at ultimate strength for 9 $w t \%$ MWCNT/PLA nanocomposites could be explained by the high carbon nanotube concentration making the composite too crumbly and resulting in worst macromechanical properties.

Young's modulus as a function of carbon filler content for both studied monofiller composite materials is presented in Figure 9. An insignificant impact has been observed concerning the nanocomposite elasticity by adding GNP in a PLA matrix. The Young's modulus is increasing in the case of carbon nanotubes loading up to $9 \mathrm{wt} \%$ filler content. The higher elasticity that could be seen for $9 \mathrm{wt} \%$ MWCNT/PLA nanocomposites is probably a result of good filler dispersion. The loadings above $3 \mathrm{wt} \%$ of graphene lead to a slightly lower Young's modulus of the nanocomposites. This Young's modulus reduction is insignificant and might be related to some negligible inhomogeneous distribution of carbon filler in the polymer, especially at $9 \mathrm{wt} \%$ GNP concentration.

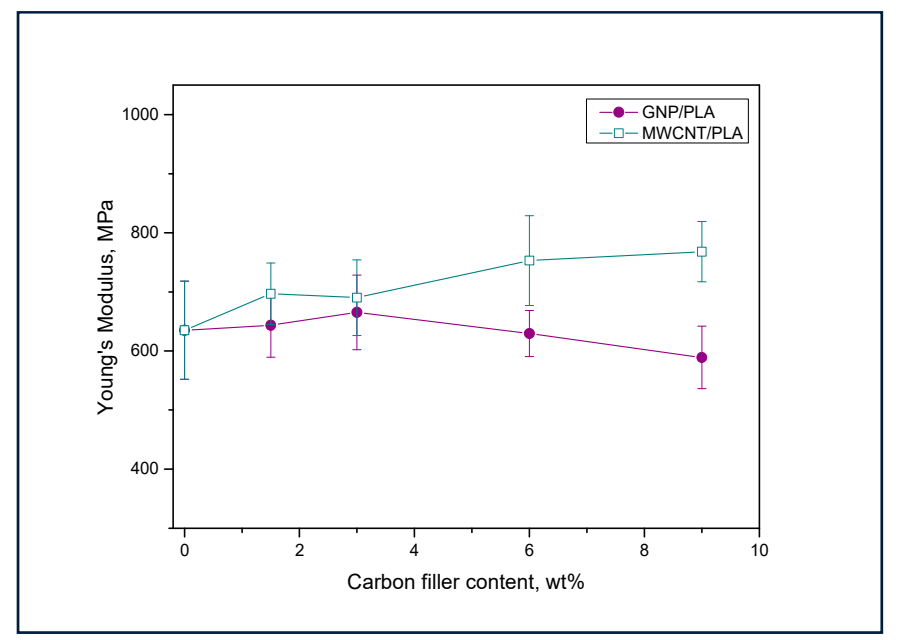

Figure 9. Tensile test results presenting Young's modulus vs. carbon nanofiller content for MWCNT/PLA and GNP/PLA composites.

\subsection{SEM Analysis}

SEM microscopy has been used to get a detailed characterization of carbon nanotubes in polymer-based nanocomposites $[53,54]$. In the present work, a series of SEM micrographs applying different magnifications were made to investigate the GNPs and MWCNTs dispersion state in the composites. Two selected SEM cross-section images of monofiller nanocomposites $9 \mathrm{wt} \%$ MWCNT/PLA (Figure 10a) and $6 \mathrm{wt} \%$ GNP/PLA (Figure 10b) disclosed a high degree of structure porosity and good uniform insertion of carbon nanofillers within the PLA matrix. 


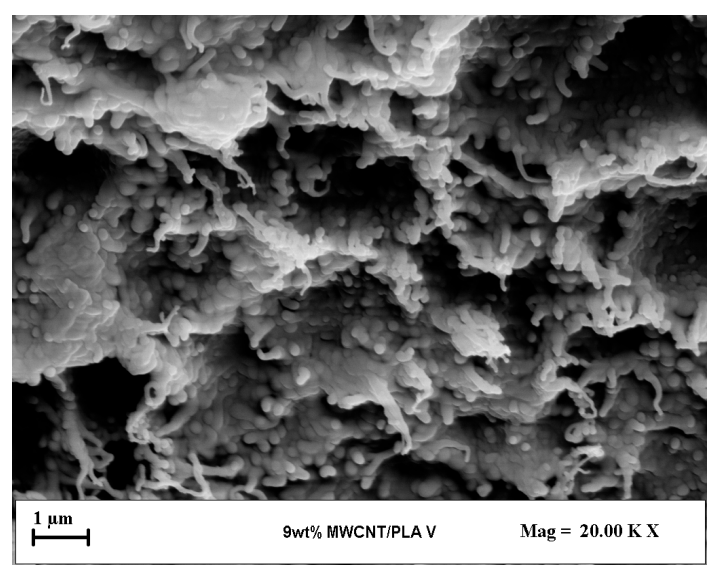

(a)

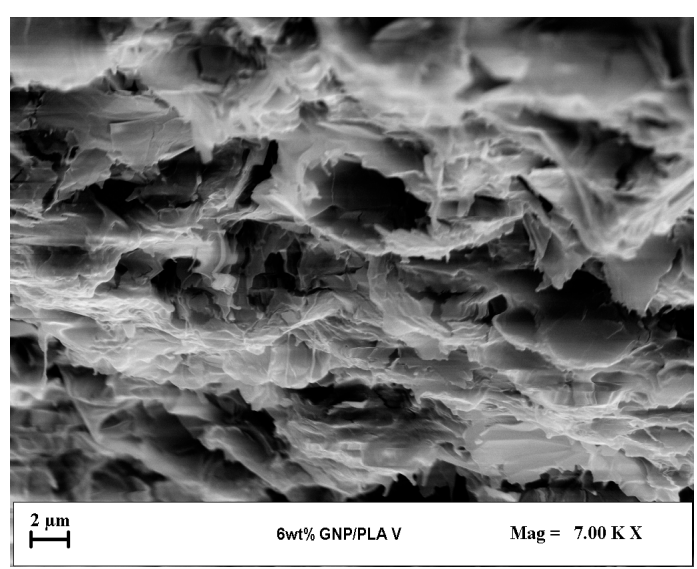

(b)

Figure 10. SEM micrographs of $9 \mathrm{wt} \%$ MWCNT/PLA (a) and $6 \mathrm{wt} \%$ GNP/PLA (b) nanocomposites.

\section{Conclusions}

Raman spectroscopy appears to be a suitable technique for analysis of the molecular morphology and structure homogeneity regarding PLA-based composites containing graphene or carbon nanotubes. The sensitivity of Raman spectroscopy to highly symmetric covalent bonds makes it capable of catching out even weak changes in structure and uncovers the method as a valuable tool in the characterization of carbon nanomaterials. The $\mathrm{I}_{\mathrm{D}} / \mathrm{I}_{\mathrm{G}}$ and $\mathrm{I}_{2 \mathrm{D}} / \mathrm{I}_{\mathrm{G}}$ ratios of the nanocomposites are an indication that above $3 \mathrm{wt} \%$ carbon filler loading the MWCNT's influence on the compound's chemical structure and properties is more significant.

The effect of multi walled carbon nanotubes on composite crystallinity is noticeable and rises with nanocomposite loading. This fact correlates to the received higher tensile strength, elongation at ultimate strength and Young's modulus values for composites reinforced with carbon nanotubes compared to the neat PLA. The incorporation of graphene in the composite matrix seems to have the opposite influence as the crystalline properties of PLA completely disappear at $9 \mathrm{wt} \%$ GNP loading. Carbon nanotubes promoted higher compound crystallinity, which could be a result of their higher degree of functionalization, where carboxyl groups can act as crystallinity centers in the polymer matrix. XRD tests of graphene nanocomposites revealed that the spacing between the platelets in the nanocomposites was slightly affected by the shearing during melt-mixing, resulting in a shift in the graphite (002) peak position. Generally, by increasing the carbon nanotube content, the tensile properties are improved as a result of better filler dispersion in the polymer matrix, confirmed as well by SEM analysis.

Author Contributions: The study was conceived and designed by R.K. and P.C.; T.B. and I.P.-D. performed tensile experiments; V.G. and V.A. were involved in nanocomposites extrusion and samples preparation; T.B., M.C. and C.C. made Raman and XRD investigations; T.B. and R.A. fulfilled SEM analysis; M.S. and E.I. analyzed the data; T.B. wrote the paper.

Funding: This work has received funding from the European Union's Horizon 2020-MSCA-RISE-734164 Graphene 3D Project.

Acknowledgments: Authors from OLEM and NanoTech Lab are grateful to the support from H2020-SGA-FET-GRAPHENE-2017-785219 Graphene Core 2.

Conflicts of Interest: The authors declare no conflict of interest.

\section{References}

1. Byrne, M.T.; Gun'ko, Y.K. Recent advances in research on carbon nanotube-polymer composites. Adv. Mater. 2010, 22, 1672-1688. [CrossRef] 
2. Moniruzzaman, M.; Winey, K.I. Polymer nanocomposites containing carbon nanotubes. Macromolecules 2006, 39, 5194-5205. [CrossRef]

3. Tasis, D.; Tagmatarchis, N.; Bianco, A.; Prato, M. Chemistry of carbon nanotubes. Chem. Rev. 2006, 106, 1105-1136. [CrossRef]

4. Stankovich, S.; Dikin, D.A.; Dommett, G.H.B.; Kohlhaas, K.M.; Zimney, E.J.; Stach, E.A.; Piner, R.D.; Nguyen, S.T.; Ruoff, R.S. Graphene-based composite materials. Nature 2006, 442, 282-286. [CrossRef]

5. Pinto, A.M.; Susana, M.; Goncalves, I.C.; Gama, F.M.; Mendes, A.M.; Magalhães, F.D. Biocompatibility of poly(lactic acid) with incorporated graphene-based materials. Colloids Surf. B 2013, 104, 229-238. [CrossRef]

6. Via, M.D.; King, J.A.; Keith, J.M.; Miskioglu, I.; Cieslinski, M.J.; Anderson, J.J.; Bogucki, G.R. Tensile modulus modeling of carbon black/polycarbonate, carbon nanotube/polycarbonate, and exfoliated graphite nanoplatelet/polycarbonate composites. J. Appl. Polym. Sci. 2012, 124, 2269-2277. [CrossRef]

7. $\mathrm{Xu}, \mathrm{Z}$;; Gao, C. In situ polymerization approach to graphene-reinforced nylon-6 composites. Macromolecules 2010, 43, 6716-6723. [CrossRef]

8. Huang, Y.; Wang, X.; Jin, X.; Wang, T. Study on the PMMA/GO nanocomposites with good thermal stability prepared by in situ Pickering emulsion polymerization. J. Therm. Anal. Calorim. 2014, 117, 755-763. [CrossRef]

9. Chandrasekaran, S.; Seidel, C.; Schulte, K. Preparation and characterization of graphite nano-platelet (GNP)/epoxy nano-composite: Mechanical, electrical and thermal properties. Eur. Polym. J. 2013, 49, 3878-3888. [CrossRef]

10. Wang, J.; Wang, X.; Xu, C.; Zhang, M.; Shang, X. Preparation of graphene/poly(vinyl alcohol) nanocomposites with enhanced mechanical properties and water resistance. Polym. Int. 2011, 60, 816-822. [CrossRef]

11. Oxfall, H.; Rondin, J.; Bouquey, M.; Muller, R.; Rigdahl, M.; Rychwalski, R.W. Elongational flow mixing for manufacturing of graphite nanoplatelet/polystyrene composites. J. Appl. Polym. Sci. 2013, 128, 2679-2686. [CrossRef]

12. Murray, E.; Thompson, B.C.; Sayyar, S.; Wallace, G.G. Enzymatic degradation of graphene/polycaprolactone materials for tissue engineering. Polym. Degrad. Stab. 2015, 111, 71-77. [CrossRef]

13. Quiles-Díaz, S.; Enrique-Jimenez, P.; Papageorgiou, D.G.; Ania, F.; Flores, A.; Kinloch, I.A.; Gómez-Fatou, M.A.; Young, R.J.; Salavagione, H.J. Influence of the chemical functionalization of graphene on the properties of polypropylene-based nanocomposites. Compos. Part A 2017, 100, 31-39. [CrossRef]

14. Bao, C.; Song, L.; Xing, W.; Yuan, B.; Wilkie, C.A.; Huang, J.; Guo, Y.; Hu, Y. Preparation of graphene by pressurized oxidation and multiplex reduction and its polymer nanocomposites by masterbatch-based melt blending. J. Mater. Chem. 2012, 22, 6088-6096. [CrossRef]

15. Raquez, J.M.; Habibi, Y.; Murariu, M.; Dubois, P. Polylactide (PLA)-based nanocomposites. Prog. Polym. Sci. 2013, 38, 1504-1542. [CrossRef]

16. Huang, Y.Y.; Terentjev, E.M. Dispersion of carbon nanotubes: Mixing, sonication, stabilization, and composite properties. Polymers 2012, 4, 275-295. [CrossRef]

17. Pinto, A.M.; Martins, J.; Moreira, J.A.; Mendes, A.M.; Magalhães, F.D. Dispersion of graphene nanoplatelets in poly(vinyl acetate) latex and effect on adhesive bond strength. Polym. Int. 2013, 62, 928-935. [CrossRef]

18. Chieng, B.W.; Ibrahim, N.A.; Wan Yunus, W.M.Z.; Hussein, M.Z. The Mechanical, Thermal and Morphological Properties of Graphene Nanoplatelets Filled Poly(lactic acid)/Epoxidized Palm Oil Blends. Sci. Res. J. 2014, 11, 1-13.

19. Valapa, R.B.; Pugazhenthi, G.; Katiyar, V. Effect of graphene content on the properties of poly(lactic acid) nanocomposites. RSC Adv. 2015, 5, 28410-28423. [CrossRef]

20. Chieng, B.W.; Ibrahim, N.A.; Wan Yunus, W.M.Z.; Hussein, M.Z.; Then, Y.Y.; Loo, Y.Y. Effects of Graphene Nanoplatelets and Reduced Graphene Oxide on Poly(lactic acid) and Plasticized Poly(lactic acid): A Comparative Study. Polymers 2014, 6, 2232-2246. [CrossRef]

21. Kashi, S.; Gupta, R.K.; Kao, N.; Bhattacharya, S.N. Preparation and Characterization of Poly Lactide and Poly (Butylene Adipate-co-Terephthalate) Nanocomposites Reinforced with Graphene Nanoplatelet. In Proceedings of the 40th Annual Condensed Matter and Materials Meeting, Wagga Wagga, Australia, 2-5 February 2016.

22. Abdal-Hay, A.; Park, S.G.; Abdel-Jaber, G.T.; Lim, J.K. Biodegradable Poly(Lactic acid)/Multiwalled Carbon Nanotube Nanocomposites Fabrication Using Casting and Hot Press Techniques. Arch. Metall. Mater. 2015, $60,1557-1559$. 
23. Bounos, G.; Andrikopoulos, K.S.; Karachalios, T.K.; Voyiatzis, G.A. Evaluation of multi-walled carbon nanotube concentrations in polymer nanocomposites by Raman spectroscopy. Carbon 2014, 76, 301-309. [CrossRef]

24. Román-Doval, R.; Morales-Corona, J.; Olayo, R.; Escamilla-Rivera, V.; Uribe-Ramírez, M.; Ortega-López, M. Evaluation of nanoparticles of hydroxyapatite and MWCNT's in scaffolds of poly lactic acid. Mater. Res. Express 2016, 3, 125402. [CrossRef]

25. Hsu, Y.W.; Wu, C.C.; Wu, S.M.; Su, C.C. Synthesis and Properties of Carbon Nanotube-Grafted Silica Nanoarchitecture-Reinforced Poly(Lactic Acid). Materials 2017, 10, 829. [CrossRef]

26. Gao, Y.; Picot, O.T.; Bilotti, E.; Peijs, T. Influence of filler size on the properties of poly(lactic acid) (PLA)/graphene nanoplatelet (GNP) nanocomposites. Eur. Polym. J. 2017, 86, 117-131. [CrossRef]

27. Li, X.; Xiao, Y.; Bergeret, A.; Longerey, M.; Che, J. Preparation of Polylactide/Graphene Composites from Liquid-Phase Exfoliated Graphite Sheets. Polym. Comp. 2014, 35, 396-403. [CrossRef]

28. Singh, D.; Iyer, P.K.; Giri, P.K. Diameter dependence of interwall separation and strain in multiwalled carbon nanotubes probed by X-ray diffraction and Raman scattering studies. Diam. Relat. Mater. 2010, 19, 1281-1288. [CrossRef]

29. Pinto, V.C.; Ramos, T.; Alves, S.; Xavier, J.; Tavares, P.; Moreira, P.M.; Guedes, R.M. Comparative failure analysis of PLA, PLA/GNP and PLA/CNT-COOH biodegradable nanocomposites thin films. Procedia Eng. 2015, 114, 635-642. [CrossRef]

30. Botta, L.; Scaffaro, R.; Sutera, F.; Mistretta, M.C. Reprocessing of PLA/Graphene Nanoplatelets Nanocomposites. Polymers 2018, 10, 18. [CrossRef]

31. Mat Desa, M.S.Z.; Hassan, A.; Arsad, A.; Mohammad, N.N.B. Mechanical properties of poly(lactic acid)/multiwalled carbon nanotubes nanocomposites. Mater. Res. Innov. 2014, 18, 14-17. [CrossRef]

32. Batakliev, T.; Georgiev, V.; Ivanov, E.; Kotsilkova, R.; Di Maio, R.; Silvestre, C.; Cimmino, S. Nanoindentation analysis of 3D printed poly(lactic acid)-based composites reinforced with graphene and multiwall carbon nanotubes. J. Appl. Polym. Sci. 2018, 136, 47260. [CrossRef]

33. Kuan, C.F.; Kuan, H.C.; Ma, C.C.M.; Chen, C.H. Mechanical and electrical properties of multi-wall carbon nanotube/poly(lactic acid) composites. J. Phys. Chem. Solids 2008, 69, 1395-1398. [CrossRef]

34. Estévez-Martínez, Y.; Velasco-Santos, C.; Martínez- Hernández, A.; Delgado, G.; Cuevas-Yáñez, E.; Alaníz-Lumbreras, D.; Duron-Torres, S.; Castaño, V.M. Grafting of Multiwalled Carbon Nanotubes with Chicken Feather Keratin. J. Nanomater. 2013, 2013, 702157. [CrossRef]

35. Yousefi, A.T.; Bagheri, S.; Shinji, K.; Rouhi, J.; Mahmood, M.R.; Ikeda, S. Fast Synthesis of Multilayer Carbon Nanotubes from Camphor Oil as an Energy Storage Material. BioMed Res. Inter. 2014, 2014, 691537.

36. Dresselhaus, M.S.; Dresselhaus, G.; Saito, R.; Jorio, A. Raman spectroscopy of carbon nanotubes. Phys. Rep. 2005, 409, 47-99. [CrossRef]

37. Osswald, S.; Flahaut, E.; Gogotsi, Y. In Situ Raman Spectroscopy Study of Oxidation of Double- and Single-Wall Carbon Nanotubes. Chem. Mater. 2006, 18, 1525-1533. [CrossRef]

38. Osswald, S.; Havel, M.; Gogotsi, Y. Monitoring oxidation of multiwalled carbon nanotubes by Raman spectroscopy. J. Raman Spectrosc. 2007, 38, 728-736. [CrossRef]

39. Jorio, A.; Saito, R.; Dresselhaus, G.; Dresselhaus, M.S. Determination of nanotubes properties by Raman spectroscopy. Philos. Trans. A Math. Phys. Eng. Sci. 2004, 362, 2311-2336. [CrossRef] [PubMed]

40. Yano, T.A.; Inouye, Y.; Kawata, S. Nanoscale uniaxial pressure effect of a carbon nanotube bundle on tip-enhanced near-field Raman spectra. Nano Lett. 2006, 6, 1269-1273. [CrossRef] [PubMed]

41. Cronin, S.B.; Swan, A.K.; Unlu, M.S.; Goldberg, B.B.; Dresselhaus, M.S.; Tinkham, M. Measuring the Uniaxial Strain of Individual Single-Wall Carbon Nanotubes: Resonance Raman Spectra of Atomic-Force-Microscope Modified Single-Wall Nanotubes. Phys. Rev. Lett. 2004, 93, 167401. [CrossRef]

42. Kumar, R.; Cronin, S.B. Raman scattering of carbon nanotube bundles under axial strain and strain-induced debundling. Phys. Rev. B 2007, 75, 155421. [CrossRef]

43. Schadler, L.S.; Giannaris, S.C.; Ajayan, P.M. Load transfer in carbon nanotube epoxy composites. Appl. Phys. Lett. 1998, 73, 3842. [CrossRef]

44. Chang, T.E.; Jensen, L.R.; Kisliuk, A.; Pipes, R.B.; Pyrz, R.; Sokolov, A. Microscopic mechanism of reinforcement in single-wall carbon nanotube/polypropylene nanocomposite. Polymer 2005, 46, 439-444. [CrossRef] 
45. Bokobza, L.; Rahmani, M.; Belin, C.; Bruneel, J.-L.; El Bounia, N.-E. Blends of carbon blacks and multiwall carbon nanotubes as reinforcing fillers for hydrocarbon rubbers. J. Polym. Sci. Part B Polym. Phys. 2008, 46, 1939-1951. [CrossRef]

46. Zhang, D.; Kandadai, M.A.; Cech, J.; Roth, S.; Curran, S. Poly(l-lactide) (PLLA)/Multiwalled Carbon Nanotube (MWCNT) Composite: Characterization and Biocompatibility Evaluation. J. Phys. Chem. B 2006, 110, 12910-12915. [CrossRef] [PubMed]

47. Vano-Herrera, K.; Misuin, A.; Vogt, K. Preparation and characterization of poly(lactic acid)/poly(methyl methacrylate) blend tablets for application in quantitative analysis by micro Raman spectroscopy. J. Raman Spectrosc. 2015, 46, 273-279. [CrossRef]

48. Casiraghi, C.; Pisana, S.; Novoselov, K.S.; Geim, A.K.; Ferrari, A.C. Raman fingerprint of charged impurities in graphene. Appl. Phys. Lett. 2007, 91, 233108. [CrossRef]

49. Bhattacharyya, A.R.; Sreekumar, T.V.; Liu, T.; Kumar, S.; Ericson, L.M.; Hauge, R.H.; Smalley, R.E. Crystallization and orientation studies in polypropylene/single wall carbon nanotube composite. Polymer 2003, 44, 2373-2377. [CrossRef]

50. Ryan, K.P.; Cadek, M.; Nicolosi, V.; Blond, D.; Ruether, M.; Armstrong, G.; Swan, H.; Fonseca, A.; Nagy, J.B.; Maser, W.K.; et al. Carbon nanotubes for reinforcement of plastics? A case study with poly(vinyl alcohol). Comp. Sci. Technol. 2007, 67, 1640-1649. [CrossRef]

51. Li, Y.; Wang, Y.; Liu, L.; Han, L.; Xiang, F.; Zhou, Z. Crystallization improvement of poly(L-lactide) induced by functionalized multiwalled carbon nanotubes. J. Polym. Sci. Part B Polym. Phys. 2009, 47, 326-339. [CrossRef]

52. Xu, J.; Chen, T.; Yang, C.; Li, Z.; Mao, Y.; Zeng, B.; Hsiao, B. Isothermal Crystallization of Poly(l-lactide) Induced by Graphene Nanosheets and Carbon Nanotubes: A Comparative Study. Macromolecules 2010, 43, 5000-5008. [CrossRef]

53. Mirkhani, S.A.; Arjmand, M.; Sadeghi, S.; Krause, B.; Pötschke, P.; Sundararaj, U. Impact of synthesis temperature on morphology, rheology and electromagnetic interference shielding of CVD-grown carbon nanotube/polyvinylidene fluoride nanocomposites. Synth. Met. 2017, 230, 39-50. [CrossRef]

54. Keteklahijani, Y.Z.; Arjmand, M.; Sundararaj, U. Cobalt Catalyst Grown Carbon Nanotube/Poly(Vinylidene Fluoride) Nanocomposites: Effect of Synthesis Temperature on Morphology, Electrical Conductivity and Electromagnetic Interference Shielding. ChemistrySelect 2017, 2, 10271-10284. [CrossRef] 